\title{
Textual Appropriation and Attribution in Engineering Theses and Disserta- tions: An Exploratory Study
}

\section{Mr. Edward J. Eckel, Western Michigan University}

Edward Eckel received a B.S. degree in biology from Cornell University, Ithaca, NY, and a Master's in Library and Information Science from Drexel University, Philadelphia. Currently he is an engineering and applied sciences librarian at Western Michigan University Libraries. His work has appeared in Science and Engineering Ethics, College \& Undergraduate Libraries, Issues in Science and Technology Librarianship, Internet Reference Services Quarterly, and Reference \& User Services Quarterly. His research interests include plagiarism and research skills training in engineering graduates and undergraduates. 


\section{Textual Appropriation and Attribution in Engineering Theses and Dissertations: An Exploratory Study}

\section{Introduction}

A key assumption in the academic world is that the writing submitted for publication by a scholar is the scholar's original work. This assumption naturally extends to the work submitted by graduate students for a master's or doctoral-level degree. That said, scholarly work is rarely $100 \%$ original. Due to the need to refer to previous research results to provide a context for current research, ${ }^{1}$ academic writing is often inherently intertextual in nature. ${ }^{2}$ While the boundary line between appropriate source text use and plagiarism may be vague for some students, ${ }^{3}$ the consequences for crossing that line, even inadvertently, are not. Students and researchers accused of plagiarism can suffer serious consequences.

In 2006, 55 theses and dissertations at Ohio University's Russ College of Engineering and Technology were investigated due to allegations of plagiarism, with at least one student having his degree revoked. ${ }^{4,5}$ In 2007, a number of papers previously submitted by international physicists to the arXiv preprint server were found to be partially plagiarized. ${ }^{6,7}$ One of the accused physicists in the arXiv incident wrote a letter to the editors of the journal Nature afterward, attempting to justify his use of verbatim source material as a result of English being his second language. ${ }^{8}$ In 2008, an electrical engineering researcher published an apology in an IEEE magazine for submitting a research paper containing plagiarized material. ${ }^{9}$

While these isolated events cannot necessarily be considered a distinct pattern, they contribute to a public perception that plagiarism is a problem in engineering and applied sciences. It is therefore worth asking if engineering graduate students are being adequately trained to competently negotiate the intertextual world of scholarly writing before they move on in their research careers. The following exploratory study attempts to provide some preliminary data on how engineering graduate students use and attribute verbatim source text in their theses and dissertations and the implications of such use.

\section{Literature Review}

Plagiarism, textual copying or textual appropriation is commonly defined as the unattributed use of words, ideas, or data from other sources in academic writing. ${ }^{10,11,12}$ Some institutional definitions include the "intention to deceive" 13 but not all do, hence leaving open the possibility of unintentional copying being classified as plagiarism. While most degrees of plagiarism are generally considered inappropriate and unacceptable in academic writing, ${ }^{10,14,15,16}$ an alternate view proposed by a number of composition and linguistics researchers argues that many instances of student (and even faculty) academic plagiarism may stem from difficulties in understanding and synthesizing source text rather than deliberate dishonesty. ${ }^{17,18,19,20,21}$ These skills can be particularly challenging for international students for whom English is a second language (ESL) due to their often more limited vocabulary, making the construction of alternative ways of rephrasing source material more difficult. ${ }^{8,22,23,24,25,26}$ Furthermore, despite 
the general consistency of institutional definitions of plagiarism, ${ }^{13}$ there may be real differences in how individuals, cultures and disciplines define what is inappropriate as far as textual borrowing and attribution are concerned. ${ }^{2,3,27,28,29,30}$

In addition, there is some tenuous evidence that verbatim textual appropriation that involves mainly words rather than complete ideas or research results may be tacitly accepted in science and technology disciplines. According to two engineering professors at Ohio University, interviewed in response to the 2006 graduate plagiarism scandal, ${ }^{5,27}$ copying of sources may often be condoned or overlooked in the literature reviews of engineering theses since these sections are not always expected to be very original. Likewise, Crocker and Shaw ${ }^{2}$ and $\mathrm{Shi}^{30}$ found that many STEM faculty placed a higher priority on the attribution of ideas than the attribution of words. Bouville ${ }^{31}$ argued that this was as it should be, since ideas and research results have greater value than words in science. On this basis, Johnson ${ }^{32}$ advocated for a different threshold for a finding of plagiarism in science and technology writing, while at the same time admitting that there are still limits to legitimate textual appropriation, even in the sciences. That said, there appears to be little conclusive evidence in the literature to support the contention that plagiarism is a common occurrence in graduate engineering writing.

While several recent studies have examined the academic integrity of engineering undergraduates (copying on exams and in research papers), ${ }^{33,34,35,36,37}$ as well as copying of proprietary software code ${ }^{38}$ there are relatively few studies that have focused on engineering graduate students or their writings, with most centered around surveys of students or faculty. Brown $^{39}$ found that $18.2 \%$ of graduate engineering students surveyed admitted engaging in plagiarism "more than infrequently." In a subsequent paper drawn from the same study, Brown ${ }^{40}$ indicated that engineering graduate students were no more likely to engage in unethical academic behavior than business or education graduate students. In one survey of faculty and doctoral students in chemistry, engineering, microbiology, and sociology, $45 \%$ of civil engineering faculty reported seeing plagiarism by their graduate students, a higher percentage than for the other disciplines. ${ }^{41}$ McCullough and Holmberg ${ }^{42}$ reported that $27 \%$ of master's theses analyzed for plagiarism using Google contained copied materials, with more matches originating in the engineering-related theses than in those from other disciplines. However, due to the small search time spent per thesis and the lack of context for the resulting text matches, those results are difficult to interpret. Conversely, Gilmore et al. ${ }^{25}$ found that engineering graduate students were less likely to plagiarize in research proposals than students in other science and technology fields. Eckel ${ }^{43}$ used Google to search strings of text from 100 engineering master's theses, finding 28 theses with copied sections over 50 words in a row, seven of which had copied more than a page total verbatim. Finally, Vieyra et al., ${ }^{44}$ in a follow-up to the Gilmore et al. ${ }^{25}$ study, looked at plagiarism in 115 graduate research proposals. They found that $24 \%$ of the engineering proposals contained some plagiarized material, with the copying occurring most frequently in the introduction sections.

Based on experience this researcher has had examining patterns of textual copying in engineering theses and dissertations at his own institution, master's students appear to have more difficulty using source text appropriately than doctoral students. This ad hoc observation seems to find some tentative support from Gilmore et al., ${ }^{25}$ who found that graduate students with an average of one semester less prior research experience were more likely to copy material from their sources. A study comparing patterns of textual appropriation in graduate engineering 
master's theses and doctoral dissertations would add some more definite data to the studies that have been done so far, providing a clearer picture of graduate engineering student source use and attribution. However, any comparison of the incidence of textual appropriation in engineering to other disciplines is beyond the scope of this study.

\section{Methodology}

This exploratory study investigates the following research questions:

1. Do the literature review sections of engineering master's theses contain longer verbatim text matches than the corresponding sections of engineering doctoral dissertations? In other words, are master's engineering students copying longer word-for-word sections from their sources than doctoral students?

2. Do the literature review sections of engineering master's theses contain more verbatim text matches than the corresponding sections of doctoral dissertations?

3. Do master's engineering students attribute more or less of the verbatim source material they use than doctoral engineering students?

The basic methodology for this study was adapted from an earlier pilot study by this researcher. ${ }^{43}$ The author obtained from the ProQuest database company an Excel spreadsheet of all the English language theses and doctoral dissertations with a completion date of 2009 that included the subject heading "engineering" and were available as full text Adobe PDFs in the ProQuest Dissertations and Theses database. This initial spreadsheet included 727 master's theses and 6298 doctoral dissertations. A random sample of 150 theses and 150 doctoral dissertations was extracted from this spreadsheet. Table I shows the distribution of the sample English language engineering theses and dissertations by country. Theses from 43 different institutions and dissertations from 79 different institutions were included in the sample.

\begin{tabular}{lcc}
\hline \multicolumn{1}{c}{ Country } & Number of Theses & Number of Dissertations \\
\hline USA & 150 & 138 \\
Canada & 0 & 10 \\
Hong Kong & 0 & 2 \\
Total & 150 & 150 \\
\hline
\end{tabular}

Table I: 2009 Engineering Master's Theses and Dissertations by Country

This study focused on documenting verbatim copying or textual appropriation ${ }^{44}$ in the literature review sections of these engineering theses and dissertations because this is the main section where source materials are expected to be referenced. No attempt was made to classify copied material as transgressive in nature ${ }^{3}$ due to the difficulty of determining plagiarism based solely on textual matches. ${ }^{43}$ The Google search engine was utilized as a plagiarism checker, since this researcher's university did not have a subscription for Turnitin.com. In addition, most 
commercial plagiarism detection services require permission from the original authors before documents may be submitted for checking. This would not have been feasible in this study.

The first seven words from the first line of each literature review section, and every subsequent fifth line, were chosen for searching, for a total of thirty searches per thesis/dissertation. The seven word string length was selected based upon work by Sorokina et al. ${ }^{46}$ Each seven word string was searched as a phrase enclosed in quotation marks in the Google search engine. If the initial string retrieved too many web hits, it was lengthened with additional words from the thesis/dissertation, until either the longest verbatim source match was found or a "No results found" message was obtained. Then the word length of the verbatim string was counted and recorded. Longer copied sections that were slightly modified (by insertion of synonyms, word replacement or minor reordering) were counted as multiple short verbatim sections, with each section counted separately.

The following basic information was recorded for each source found: the exact string searched, the page number of the dissertation or thesis where the string originated, the source title and type (journal, book, etc.), the publication year, the source URL, the number of consecutive words that were copied, the page number in the source where the original text was found (when possible), and whether or not attribution was provided for the copied section.

For the purposes of this study, a Web document was considered a source of the string from the thesis/dissertation if it met the following conditions:

- It was cited by the thesis/dissertation author, or

- No other matching sources were found, and

- It was published or posted before or during 2009 (since the graduate authors quite frequently cited sources that were published during the same year they completed their theses/dissertations).

A number of word-for-word matches were excluded from this study. This included matches to anything authored/co-authored by the thesis/dissertation authors (articles, book chapters or publicly posted thesis/dissertation copies), since such "self-plagiarism" was outside the scope of this project. In addition, it quickly became apparent after data collection began that verbatim text matches of seven words were so generic that it could not be reliably established that these were indeed appropriated. Hence, for the purpose of this study, only text matches that were eight words in length or longer were counted as copied. This means that theses and dissertations that only had copied phrases seven words or less in length were coded as having no copied strings. Finally, since this study focused on textual copying, copied figures or charts were also excluded.

To answer the three research questions, the following measures from the data were examined: the longest verbatim copied text string per thesis/dissertation, and the percentage of searches out of the 30 total per thesis/dissertation that retrieved verbatim sources. Since an essential part of most institutional definitions of plagiarism is the lack of attribution for copied material, ${ }^{11,12,13,47}$ the proportion of the appropriated strings that were attributed by the master's and doctoral students was also analyzed. 


\section{Results}

\section{a) Longest Verbatim Text String}

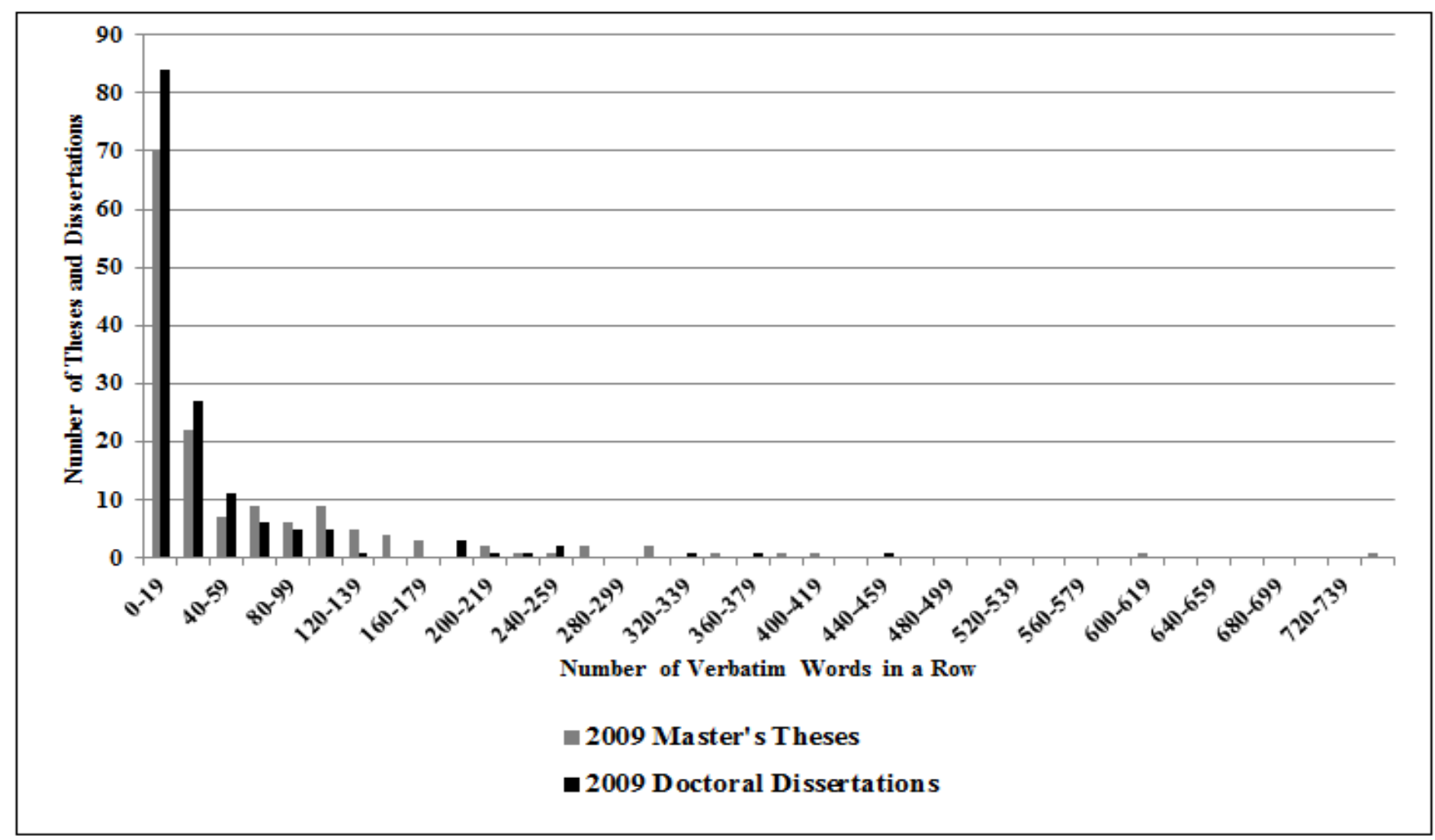

Figure 1: Length of Longest Verbatim String (per Thesis/Dissertation) - excluding data points above 1000 .

Figure 1 shows the distributions of the longest verbatim text string above 8 words in length for the theses and dissertations. The $\mathrm{X}$-axis shows the number of verbatim words copied in a row (in 20 word increments) and the $\mathrm{Y}$-axis shows the number of theses and dissertations in each 20 word range. To keep the distributions in Figure 1 readable, two data points above 1000 were excluded from the master's thesis results (2761 and 2110 words-in-a-row) and one data point above 1000 was excluded from the dissertation results (1048 words-in-a-row). As can be seen in Figure 1, both distributions are very skewed, with a lot of zeros (no copied text) and low values in each sample. This is to be expected - most students probably do not engage in copying or do so with short strings. Figure 2 shows a box plot of the same datasets, with all data points included. 


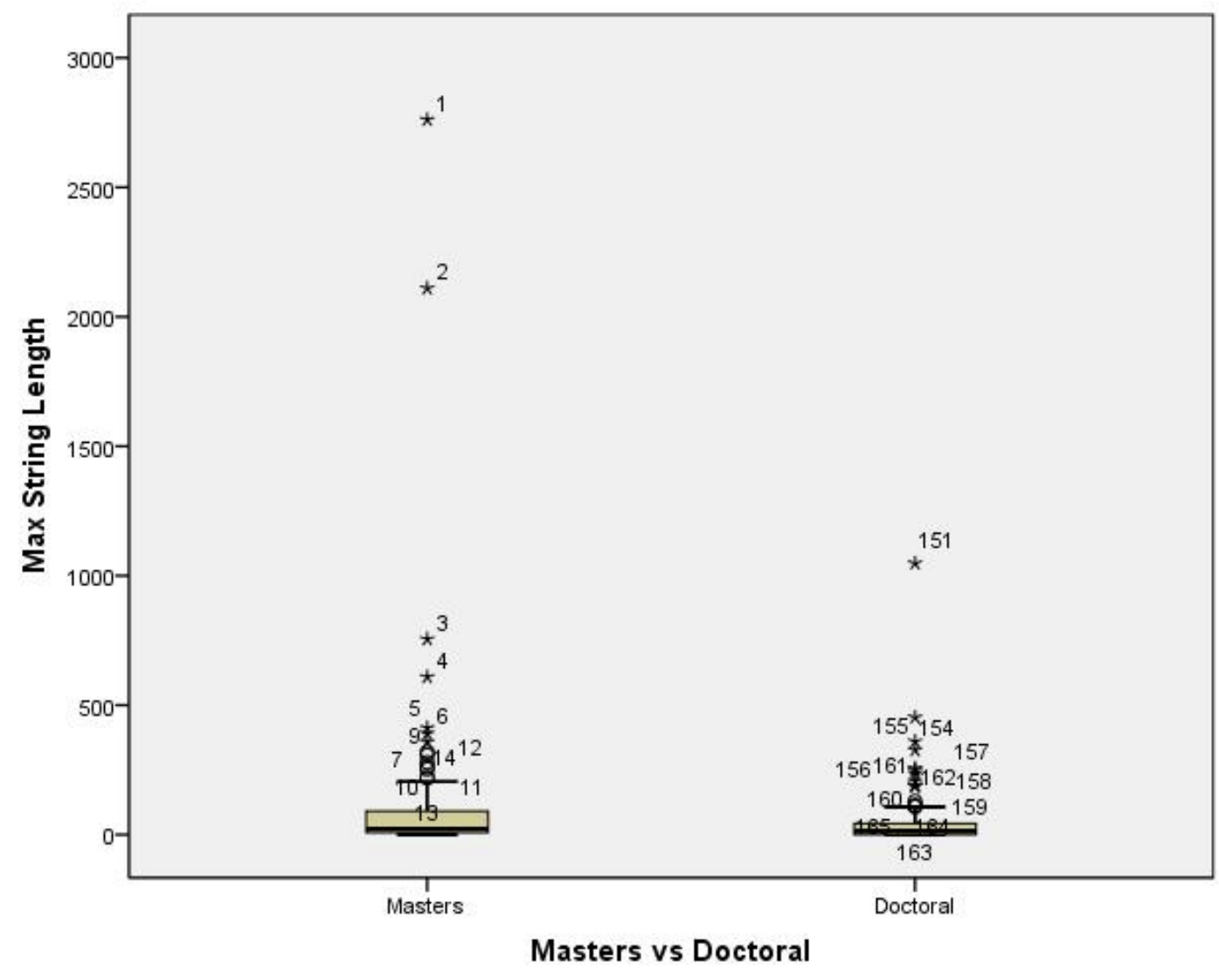

Figure 2: Box Plot - Length of Longest Verbatim String (per Thesis/Dissertation)

\begin{tabular}{|c|c|c|c|c|c|c|}
\hline & \multicolumn{6}{|c|}{ Percentiles } \\
\hline & Mean & Min & 25 th & 50th (Median) & 75 th & Max \\
\hline $\begin{array}{l}2009 \text { Master's } \\
\text { Theses }\end{array}$ & 98 & 0 & 8.00 & 22.50 & 91.75 & 2761 \\
\hline 2009 Dissertations & 47 & 0 & 0.00 & 14.00 & 43.25 & 1048 \\
\hline
\end{tabular}

Table II: Longest Verbatim String - Descriptive Statistics 


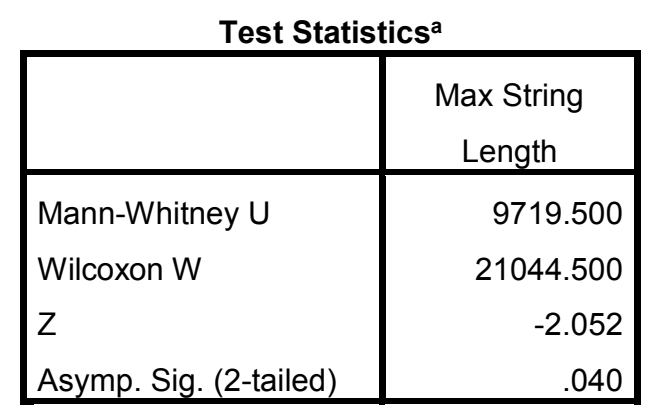

a. Grouping Variable: Master's vs Doctoral

Table III: Mann-Whitney Test Results - Longest Verbatim String

Table II shows descriptive statistics for the thesis and dissertation samples. Table III shows the results of a Mann-Whitney U test (SPSS version 19.0) done on the data sets for the two groups. The Mann-Whitney U test is a non-parametric statistical test used to determine if the null hypothesis can be rejected for two independent sample populations. ${ }^{48}$ The medians of the two samples (master's versus doctoral) were 22.5 and 14 verbatim words in a row respectively; the distributions of the two groups differed significantly (Mann-Whitney $\mathrm{U}=9719.5, \mathrm{P}<0.05$ twotailed). Hence, the two populations were found to differ significantly in the length of the longest copied strings, with the master's students copying longer verbatim strings on average than the doctoral students.

\section{b) Percentage of Verbatim Hits (/30)}

Figure 3 displays the distributions of the percentage of verbatim hits obtained out of the total 30 searches done per thesis/dissertation (X-axis), along with the number of theses and dissertations in each percentage category (Y-axis). As can be seen, these two distributions are skewed (although less so than for the longest verbatim string in Figure 1), with the master's theses having a longer tail than the dissertations. The highest percentage of verbatim hits found for any dissertation was $60 \%$, whereas the highest percentage for theses was $100 \%$, a thesis in which every single Google search found a verbatim source. Figure 4 shows a box plot of the same datasets. While the boxes for both samples are negatively skewed, the master's theses are much more negatively skewed than the doctoral dissertations, indicating that the master's theses tended to have larger percentages of copied material. 


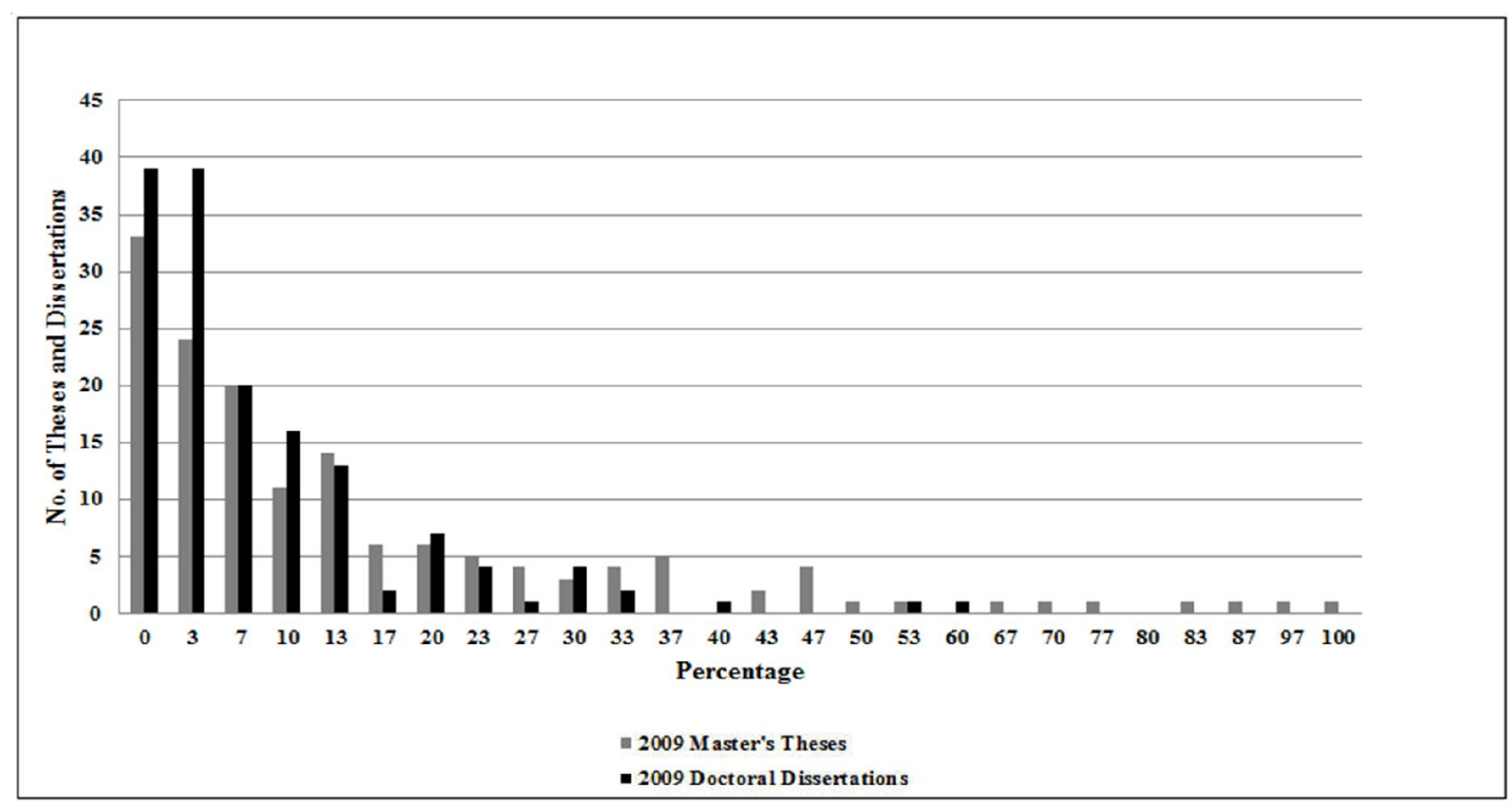

Figure 3: Percentage of Verbatim Hits (Out of 30 Searches)

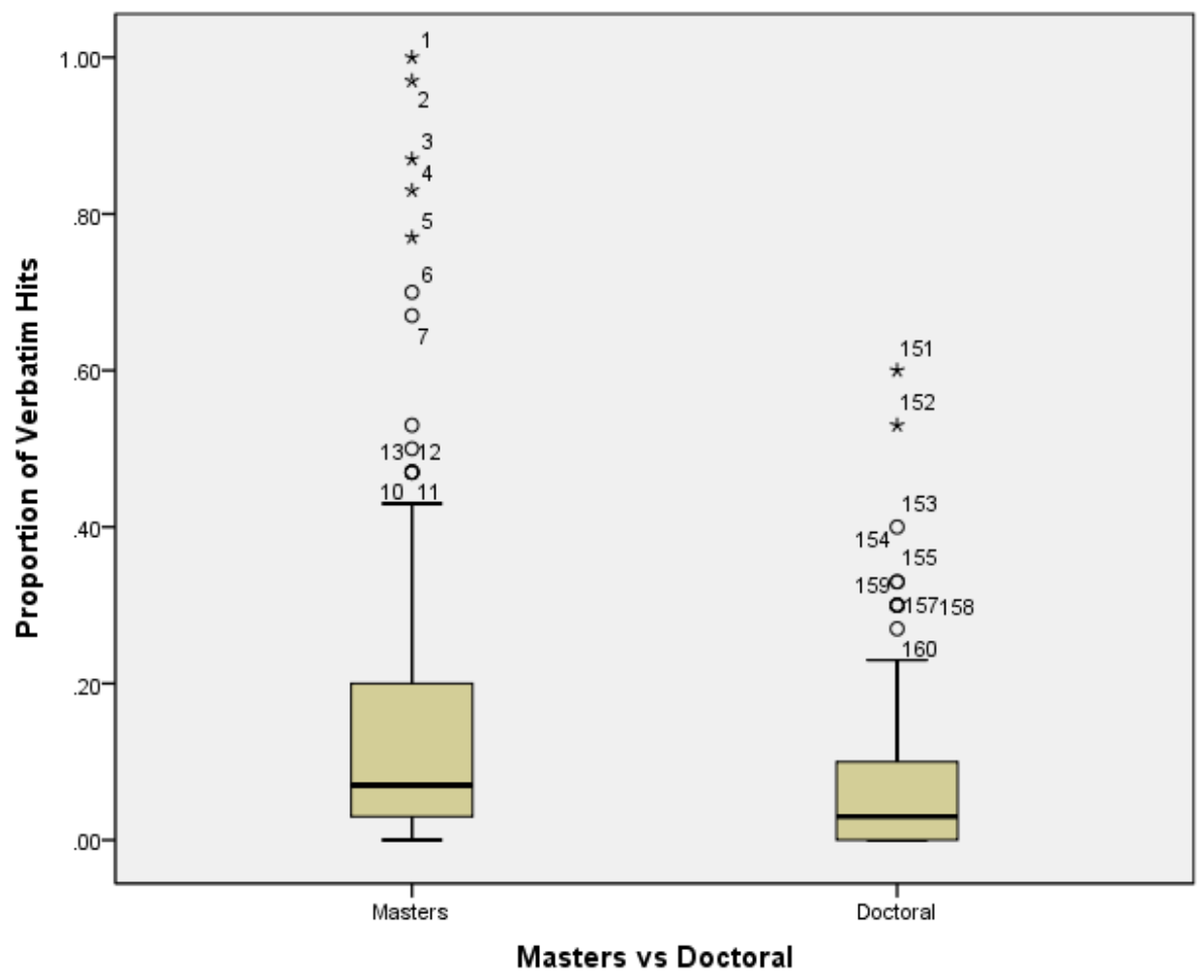

Figure 4: Box Plot - Percentage of Verbatim Hits (Out of 30 Searches) 
Table IV shows descriptive statistics for the two sample populations on this measure. Table V shows the results of a Mann-Whitney $U$ test done on the data sets for the two groups. The medians of the two samples (master's versus doctoral) were .07 and .03 respectively (Table IV); the distributions of the two groups differed significantly (Mann-Whitney $\mathrm{U}=9042, \mathrm{P}<0.01$ two-tailed). The Mann-Whitney test results indicate that the difference between the two populations is highly significant on this measure, suggesting that master's engineering students copied significantly more strings in (and hence a larger proportion of) their literature reviews than the doctoral engineering students.

\begin{tabular}{|c|c|c|c|c|c|c|}
\hline & \multicolumn{6}{|c|}{ Percentiles } \\
\hline & Mean & Min & 25 th & 50th (Median) & 75 th & Max \\
\hline $\begin{array}{l}2009 \text { Master's } \\
\text { Theses }\end{array}$ & 0.15 & 0.00 & 0.03 & 0.07 & 0.20 & 1.00 \\
\hline 2009 Dissertations & 0.08 & 0.00 & 0.00 & 0.03 & 0.10 & 0.60 \\
\hline
\end{tabular}

Table IV: Percentage of Verbatim Hits - Descriptive Statistics

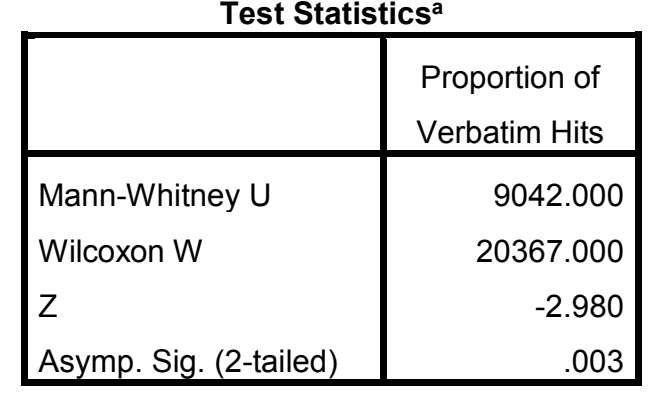

a. Grouping Variable: Master's vs Doctoral

Table V: Mann-Whitney Test Results - Percentage of Verbatim Hits

\section{c) Attribution of Verbatim Strings}

117 master's theses and 111 doctoral dissertations were found to have verbatim copied text strings 8 words or more in length. The mean percentage of verbatim strings that were attributed to sources was calculated for each thesis and dissertation. The mean percentage of attributed strings was $52 \%$ for the master's theses and $60 \%$ for the doctoral dissertations. A t-test for difference of means showed that the difference between the two populations was not significant $(p>.05)$ on this measure. Hence the master's and doctoral students appeared on average to be equally likely (or unlikely) to attribute the verbatim source material they copied in their work. 


\section{Discussion}

The doctoral dissertations in this study exhibited significantly less textual appropriation overall than the master's theses, both in terms of the word length and the total number of verbatim copied strings found. There are a number of factors that might explain this difference. Graduate students with an average of one semester less prior research experience have been shown to be more likely to copy material from their sources. ${ }^{25}$ This may be because doctoral students have more writing experience or be more familiar with the norms of academic writing in the discipline than the master's students, who themselves may have returned to graduate school with writing and citation habits conditioned by the workplace or popular culture. On the other hand, doctoral students may simply be more sensitive to the issue of plagiarism overall. In addition, doctoral students may be given more feedback from advisors and dissertation committee members about the necessity of avoiding plagiarism. Finally, it is possible that their dissertations have gotten closer scrutiny or been held to a higher standard than the master's theses, thereby exposing potential problems in advance.

However, despite the differences between the two groups on these measures, a still sizable number of both master's and doctoral students engaged in questionable levels of copying, both in terms of the length of the strings copied and the number of strings copied (Table VI). $34 \%$ of the master's engineering students copied strings of text over 60 words in length versus $19 \%$ of the doctoral students. $21 \%$ of master's engineering students copied more than $25 \%$ of the section of the literature review examined in this study verbatim from their sources (based on the percentage of verbatim hits out of 30 searches), whereas only $7 \%$ of the doctoral students did the same.

\begin{tabular}{lcc}
\hline & Master's Theses & Doctoral Dissertations \\
\hline Strings over 60 words in a row & $51(34 \%)$ & $28(19 \%)$ \\
Multiple strings over 60 words in a row & $33(22 \%)$ & $11(7 \%)$ \\
$\begin{array}{l}\text { Copied over } 25 \% \text { of literature review } \\
\text { examined }\end{array}$ & $31(21 \%)$ & $10(7 \%)$ \\
\hline
\end{tabular}

Table VI: Overall Patterns of Copying - Master's vs. Doctoral Engineering Students

In addition, both master's and doctoral engineering students provided attribution for the copied text sections only a little more than half the time. Clearly, these students should do better. However, the decisions students make regarding when and how to attribute sources are complex and contextual, dependent upon many pragmatic factors that do not easily align with disciplinary or institutional rules against copying or honor codes. ${ }^{2,3,49,50}$ In Shi's survey of undergraduates from both native English speaking and English as a Second Language (ESL) backgrounds, students from both groups found norms regarding citation and attribution confusing or contradictory. 51 


\section{Study Limitations}

It is important to note that, due to its labor-intensive nature, the data collection stage of this project spanned a nearly two year period of time (August 2010 - June 2012). There are two factors that could affect the consistency of measures of textual appropriation made over such a long time frame. One is intrarater reliability and the other is the volatility of content on the Internet. Intrarater reliability is a measure of how consistent an individual researcher or grader is in scoring or grading over a period of time. ${ }^{52}$ It is possible that the researcher's technique for counting the number of verbatim words in web hits (particularly lengthy copied sections) might shift subconsciously over time, especially as one develops habitual facility in running the searches and tabulating the results. In addition, it is possible that some sample text strings might have gotten more or less source matches on Google near the end of the data collection period compared to the beginning of the period, not due to any fault of the researcher, but rather, due to either more source material becoming available on the $w^{35}$ or to some sources disappearing from the web altogether. ${ }^{53}$ It is recommended that future studies of this type incorporate a means of checking the consistency of these types of measurements taken from Google searches over time.

\section{Conclusion}

For the engineering students whose work is examined here, it appears that the confusion regarding what and how much verbatim source material can be legitimately appropriated and how it should be attributed was not cleared up by the time they completed their theses and dissertations. This should be a cause for concern for engineering graduate schools. Needless to say, such patterns of textual copying and lack of attribution are problematic at best and could get these students in trouble, either in graduate school or beyond, were they to continue with this behavior. ${ }^{13,54}$ However, one could also argue that this is what we can realistically expect from novice writers in the field of engineering, given the level of writing instruction and practice they have received up to this point in their educational journey ${ }^{49}$ and the pressures they are under to produce authoritative-sounding texts before they are truly 'authorities. ${ }^{55}$ Both Parry ${ }^{56}$ and Boote and Beile ${ }^{57}$ have asserted that graduate programs appear to give their students little explicit training in these writing skills. What can be done to improve how graduate engineering students engage with and attribute their sources?

A number of insightful ways of addressing this lack of graduate writing preparation are discussed in the literature. First, several researchers recommend that faculty move beyond simple exhortations against plagiarism into an active and engaged discussion with students to clarify the writing and attribution norms of the discipline. ${ }^{29,58,59}$ Helping students to take ownership of this issue can mitigate resistance to discussing it. Dong ${ }^{23,24}$ and Pecorari ${ }^{28}$ recommend that transparent source use be explicitly taught (rather than just mentioned) at the college level. Furthermore, there is a fair amount of evidence that one becomes more effective in the appropriate use of source materials with cumulative writing practice, ${ }^{59,60}$ particularly practice in paraphrasing and summary writing. ${ }^{17,18,19,24,61,62,63}$

Some composition researchers recommend exposing students, particularly ESL students, to disciplinary writing norms and rhetorical practices via guided interaction with the published 


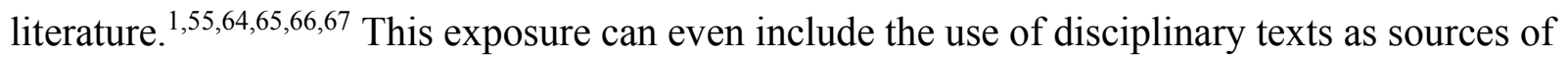
useful generic phraseology, common expressions, and article structures for legitimate imitation and borrowing purposes. ${ }^{29,64,68,69,70}$

The researcher has collaborated with the graduate college at his own university in offering a periodic workshop that provides graduate students with information about different types of plagiarism and the kinds of problems graduate students exhibit with regards to source text use, as well as techniques for engaging with sources in such a way as to avoid the extreme types of plagiarism seen in this study. This is a "workshop-in-progress," so to speak. A series of video tutorial modules have been created and linked in an online guide. ${ }^{71}$ It is hoped that some version of this workshop, along with the attendant online videos, can be adapted by individual departments who wish to address these issues within a disciplinary framework. Who better to illuminate the rhetorical nature and expectations of engineering writing than the engineering faculty, and in particular the thesis/dissertation advisors? Faculty who attempt to start this conversation with their graduate students should be prepared, however, for some initial resistance, along with pleas of "I know this already."

More importantly, graduate programs may need to consider integrating this kind of plagiarism awareness and writing instruction more completely into the graduate curriculum, to make sure that all students are adequately prepared for the rigors of the thesis or dissertation literature review. ${ }^{57}$ Otherwise these programs risk sending their freshly minted graduates out into academia and the working world where they will perpetuate this kind of copying.

\section{Acknowledgements}

The author would like to thank Austin McLean and Mary Ann Gilbert of ProQuest for their assistance in obtaining a complete Excel spreadsheet of all 2009 engineering-related theses and dissertations in the ProQuest database. In addition, Dr. Jeffrey Terpstra, professor of statistics at Western Michigan University, did the initial statistical calculations necessary to determine the sample size for this project. His assistance was invaluable in getting this project started. Finally, Robert McNutt and Dr. Joshua Naranjo of the Statistical Consulting Center assisted with the final statistical analysis.

\section{Bibliography}

1. Swales, J. M. (1987). Utilizing the literatures in teaching the research paper. TESOL Quarterly, 21(1), 4168.

2. Crocker, J., \& Shaw, P. (2002). Research student and supervisor evaluation of intertextuality practices. Hermes Journal of Linguistics, 28, 39-58.

3. Chandrasoma, R., Thompson, C., \& Pennycook, A. (2004). Beyond plagiarism: Transgressive and nontransgressive intertextuality Journal of Language, Identity, and Education, 3(3), 171-193.

4. Linder, S. (2007, March 28). Ohio University revokes master's degree: Student found guilty of plagiarism. Outlook: Ohio University News \& Information. Retrieved from http://www.ohio.edu/outlook/0607/March/457n-067.cfm

5. Wasley, P. (2006, September 8). Panel to review plagiarism at Ohio U. The Chronicle of Higher Education, 53, A9. 
6. Brumfiel, G. (2007). Turkish physicists face accusations of plagiarism. [news]. Nature, 449(7158), 8. doi: $10.1038 / 449008 b$

7. Woit, P. (2008, January 10, 2008). Update on Plagiarism Scandal. Not Even Wrong [Blog], from $\mathrm{http} / / /$ www.math.columbia.edu/ woit/wordpress/?p=638

8. Yilmaz, I. (2007). Plagiarism? No, we're just borrowing better English. Nature, 449(7163), 658.

9. Baker, A. (2008). Apology [Plagiarism]. [Letter to the Editor]. IEEE Circuits and Systems Magazine, 8(3), 95. doi:10.1109/MCAS.2008.923978

10. IEEE. (2012). A Plagiarism FAQ. Retrieved from http://www.ieee.org/publications_standards/publications/rights/plagiarism_FAQ.html

11. Research Misconduct [National Science Foundation], 45 CFR 689 C.F.R. (2002).

12. Western Michigan University. (2006). Research Misconduct Policy and Procedures. Retrieved from http://www.wmich.edu/research/pdf/policies/research-misconduct-policy2006.pdf

13. Pecorari, D., Belcher, D., \& Hirvela, A. (2001). Plagiarism and international students: How the Englishspeaking university responds. In D. Belcher \& A. Hirvela (Eds.), Linking literacies: Perspectives on L2 reading-writing connections (pp. 229-245). Ann Arbor: University of Michigan Press.

14. Casandras, C. G. (2012). Plagiarism and other sins [President's message]. IEEE Control Systems Magazine, 32(4), 10-12. doi:10.1109/MCS.2012.2194834

15. Hexham, I. (2005). Academic Plagiarism Defined. Retrieved from http://www.ucalgary.ca/ hexham/study/plag.html

16. Maddox, J. (1995). Plagiarism is worse than mere theft. [Viewpoint article]. Nature, 376(6543), 721.

17. Brogan, K. M., \& Brogan, J. D. (1982, April). Yet another ethical problem in technical writing. Paper presented at the 13th Annual Meeting of the College English Association, Houston, TX.

18. Campbell, C. (1990). Writing with others' words: Using background reading text in academic compositions. In B. Knoll (Ed.), Second language writing: Research insights for the classroom (pp. 211-230). New York: Cambridge University Press.

19. Howard, R. M. (1999). Standing in the shadow of giants: Plagiarists, authors, collaborators. Stamford, CT: Ablex Pub.

20. Parkhurst, C. (1990). The composition process of science writers. English for Specific Purposes, 9(2), 169179.

21. Roig, M. (2001). Plagiarism and paraphrasing criteria of college and university professors. Ethics \& Behavior, 11(3), 307-323.

22. Angelil-Carter, S. (2000). Stolen language? Plagiarism in writing. London: Longman.

23. Dong, Y. R. (1996). Learning how to use citations for knowledge transformation: Non-native doctoral students' dissertation writing in science. Research in the Teaching of English, 30(4), 428-457.

24. Dong, Y. R. (1998). Non-native graduate students' thesis/dissertation writing in science: Self-reports by students and their advisors from two U.S. institutions. English for Specific Purposes, 17(4), 369-390.

25. Gilmore, J. G., Strickland, D., Timmerman, B., Maher, M., \& Feldon, D. (2010). Weeds in the flower garden: An exploration of plagiarism in graduate students' research proposals and its connection to enculturation, ESL, and contextual factors. International Journal for Educational Integrity, 6(1), 13-28.

26. Keck, C. (2006). The use of paraphrase in summary writing: A comparison of L1 and L2 writers. Journal of Second Language Writing, 15(4), 261-278.

27. Grose, T. K. (2006). The burden of plagiarism. ASEE Prism, 16(2), 36-39.

28. Pecorari, D. (2008). Academic writing and plagiarism: A linguistic analysis. London; New York: Continuum.

29. Pecorari, D., \& Shaw, P. (2012). Types of student intertextuality and faculty attitudes. Journal of Second Language Writing, 21(2), 149-164. doi:10.1016/j.jslw.2012.03.006

30. Shi, L. (2012). Rewriting and paraphrasing source texts in second language writing. Journal of Second Language Writing, 21(2), 134-148. doi:10.1016/j.jslw.2012.03.003

31. Bouville, M. (2008). Plagiarism: Words and ideas. Science and Engineering Ethics, 14(3), 311-322. 
32. Johnson, A. T. (2010). Threshold for plagiarism. [Letter to the Editor]. IEEE Engineering in Medicine and Biology Magazine, 29(2), 6. doi:10.1109/MEMB.2009.935716

33. Carpenter, D. D., Harding, T. S., Finelli, C. J., Montgomery, S. M., \& Passow, H. J. (2006). Engineering students' perceptions of and attitudes towards cheating. Journal of Engineering Education, 95(3), 181-194.

34. Carpenter, D. D., Harding, T. S., \& Finelli, C. J. (2010). Using research to identify academic dishonesty deterrents among engineering undergraduates. International Journal of Engineering Education, 26(5), 1156-1165.

35. Culwin, F. (2008). A longitudinal study of nonoriginal content in final-year computing undergraduate projects. IEEE Transactions on Education, 51(2), 189-194. doi:10.1109/te.2007.910350

36. Harding, T. S., Carpenter, D. D., \& Finelli, C. J. (2012). An exploratory investigation of the ethical behavior of engineering undergraduates. Journal of Engineering Education, 101(2), 346-374.

37. McCabe, D. L. (1997). Classroom cheating among natural science and engineering majors. Science and Engineering Ethics, 3(4), 433-445.

38. Rosales, F., Garcia, A., Rodriguez, S., Pedraza, J.L., Mendez, R., \& Nieto, M.M. (2008). Detection of plagiarism in programming assignments. IEEE Transactions on Education 51(2): 174-183.

39. Brown, B. S. (1994). The academic ethics of graduate engineering students. Chemical Engineering Education, 28, 242-243, 265.

40. Brown, B. S. (1996). A comparison of the academic ethics of graduate business, education and engineering students. College Student Journal, 30(3), 294-301.

41. Swazey, J. P., Anderson, M. S., Lewis, K. S., \& Louis, K. S. (1993). Ethical problems in academic research. American Scientist, 81(6), 542-553. doi:10.2307/29775057

42. McCullough, M., \& Holmberg, M. (2005). Using the Google search engine to detect word-for-word plagiarism in master's theses: A preliminary study. College Student Journal, 39(3), 435-441.

43. Eckel, E. J. (2011). Textual appropriation in engineering master's theses: A preliminary study. Science and Engineering Ethics 17(3), 469-483.

44. Vieyra, M., Strickland, D., \& Timmerman, B. (2013). Patterns in plagiarism and patchwriting in science and engineering graduate students' research proposals. International Journal for Educational Integrity, 9(1), 35-49.

45. Woodmansee, M., \& Jaszi, P. (Eds.). (1994). The construction of authorship: Textual appropriation in law and literature. Durham, NC: Duke University Press.

46. Sorokina, D., Gehrke, J., Warner, S., \& Ginsparg, P. (2006, December). Plagiarism detection in arXiv. Paper presented at the Sixth International Conference on Data Mining, Hong Kong. doi:10.1109/ICDM.2006.126

47. Modern Language Association. (2009). MLA handbook for writers of research papers (Vol. 7). New York: Modern Language Association of America.

48. SPSS Inc. (2006). SPSS Base 15.0 User's Guide. Chicago: SPSS Inc.

49. Pecorari, D. (2003). Good and original: Plagiarism and patchwriting in academic second-language writing. Journal of Second Language Writing, 12(4), 317-345.

50. Shi, L. (2010). Textual appropriation and citing behaviors of university undergraduates. Applied Linguistics, 31(1), 1-24.

51. Shi, L. (2006). Cultural backgrounds and textual appropriation. Language Awareness, 15(4), 264-282.

52. Moskal, B. M., \& Leydens, J. A. (2000). Scoring rubric development: Validity and reliability. Practical Assessment, Research, and Evaluation, 7(10). Retrieved from http://pareonline.net/getvn.asp? $\mathrm{v}=7 \& \mathrm{n}=10$

53. Spinellis, D. (2003). The decay and failures of web references. Communications of the ACM, 46(1), 71-77.

54. Bizzell, P. (1982). College composition: Initiation into the academic discourse community. [Book review]. Curriculum Inquiry, 12(2), 191-207.

55. Abasi, A. R., \& Akbari, N. (2008). Are we encouraging patchwriting? Reconsidering the role of the pedagogical context in ESL student writers' transgressive intertextuality. English for Specific Purposes, 27(3), 267-284. 
56. Parry, S. (1998). Disciplinary discourse in doctoral theses. Higher Education, 36(3), 273-299.

57. Boote, D. N., \& Beile, P. (2005). Scholars before researchers: On the centrality of the dissertation literature review in research preparation. Educational Researcher, 34(6), 3-15.

58. Evans, F. B., \& Youmans, M. (2000). ESL writers discuss plagiarism: The social construction of ideologies. Journal of Education, 182(3), 49-65.

59. Howard, R. M., \& Robillard, A. E. (2008). Pluralizing plagiarism: Identities, contexts, pedagogies. Portsmouth, NH: Boynton/Cook Publishers.

60. Spack, R. (1997). The acquisition of academic literacy in a second language: A longitudinal case study. Written Communication, 14(1), 3-62.

61. Krishnan, L. A., \& Kathpalia, S. S. (2002). Literature reviews in student project reports. IEEE Transactions on Professional Communication, 45(3), 187-197.

62. Li, Y. (2013). Text-based plagiarism in scientific writing: What Chinese supervisors think about copying and how to reduce it in students' writing. Science and Engineering Ethics, 19(2), 569-583. doi:10.1007/s11948-011-9342-7

63. Storch, N. (2012). Incorporation of source material: The effect of instruction. TESOL in Context, 22(1), 3855.

64. Barks, D., \& Watts, P. (2001). Textual borrowing strategies for graduate-level ESL writers. In D. Belcher \& A. Hirvela (Eds.), Linking literacies: Perspectives on L2 reading-writing connections (pp. 246-267). Ann Arbor: University of Michigan Press.

65. Currie, P. (1998). Staying out of trouble: Apparent plagiarism and academic survival. Journal of Second Language Writing, 7(1), 1-18.

66. Levis, J. M., \& Levis, G. M. (2003). A project-based approach to teaching research writing to nonnative writers. IEEE Transactions on Professional Communication, 46(3), 210-220.

67. Li, Y. Y. (2007). Apprentice scholarly writing in a community of practice: An intraview of an NNES graduate student writing a research article. TESOL Quarterly, 41(1), 55-79.

68. Bianchi, F., Pazzaglia, R., \& Facchinetti, R. (2007). Student writing of research articles in a foreign language: Metacognition and corpora. In R. Facchinetti (Ed.), Corpus linguistics 25 years on (pp. 259-287). Amsterdam and New York: Rodopi.

69. Jones, A. A., \& Freeman, T. E. (2003). Imitation, copying, and the use of models: Report writing in an introductory physics course. IEEE Transactions on Professional Communication, 46(3), 168-184.

70. Shaw, P. (1991). Science research students' composing processes. English for Specific Purposes, 10(3), 189-206.

71. Eckel, E. J. (2013). Plagiarism. Retrieved from http://libguides.wmich.edu/plagiarism. 